\title{
Meios digitais em práticas pedagógicas na educação: uma análise hermenêutica-fenomenológica
}

Digital media in pedagogical practices in education: an hermeneuticphenomenological analysis

Adriana Barroso de Azevedo* Universidade Metodista de São Paulo

Resumo O artigo aqui apresentado traz resultados de pesquisa realizada com 11 professores, indicados por serem inovadores, criativos e por possuírem práticas pedagógicas diferenciadas com uso de tecnologias, que atuam em escolas nas redes pública e privada dos municípios de São Bernardo do Campo e São Paulo. O trabalho parte da concepção da pesquisa-formação (JOSSO, 2010) e busca promover reflexão com vistas à construção de conhecimentos sobre educação e tecnologia. As narrativas das experiências docentes com uso de tecnologia, construídas em ambientes virtuais de aprendizagem, foram analisadas a partir da abordagem hermenêutica-fenomenológica (FREIRE 2012, RICOUER 1986). Os resultados apontam que as práticas não estão ancoradas no uso da tecnologia em si, mas no desejo desses educadores de promover uma educação mais humanizada e próxima do contexto de seu aluno.

PALAVRAS-CHAVE: Tecnologias digitais de informação e comunicação; Docência; Educação básica; Experiência.

Abstract This article brings the results of a research done with 11 teachers, indicated for being innovative, creative and for the use of different pedagogical practices with the usage of technology. These teachers work on public and private schools of the cities of São Bernardo do Campo and São Paulo. The article was built under the concept of research-training (JOSSO, 2010) and seeks to promote reflection towards the knowledge-building about education and technology. The narratives of teaching experiences with the use of technology, built on virtual learning environments, were analyzed from a hermeneutic-phenomenological approach (FREIRE 2012, RICOUER 1986). The results show that the practices are not anchored in the use of technology itself, but the desire of these educators to promote a education that is more humane and next to the student's context.

KEYWORDS: Digital information and communication technologies; Teaching; Basic education; Experience. 


\section{Contexto}

A matéria intitulada: "Escolas jesuítas da Catalunha apostam na renovação do modelo pedagógico para se adaptar aos novos tempos", divulgada na Revista Educação ${ }^{1}$ em setembro de 2015, traz a experiência dos diretores da Fundação Jesuítas Educação da Catalunha, na Espanha, que lideraram nos últimos anos um processo de reformulação do modelo pedagógico até então adotado em suas escolas. $\mathrm{O}$ texto apresenta o projeto de reformulação das escolas e alguns resultados da implantação e ao final da matéria, aparecem algumas frases de alunos que, ao serem instigados a pensar o futuro da escola, afirmaram seus desejos, os quais transcrevo a seguir: "Queremos salas com cores divertidas." "Uma professora bem feliz, dando beijos e abraços." "Sair para brincar na chuva com botas de borracha." "Que a sala tenha mesas redondas, iPads e um botão para abrir a porta.» «Um quadro digital para muitas crianças tocarem ao mesmo tempo.» «Uma cama elástica no pátio e um gatinho em cada sala.»

O que de fato essas crianças querem? Por que se expressam dessa forma? Alguns educadores têm nos trazido reflexões interessantes sobre a escola no contexto do século XXI. Rojo (2013, p. 7) acredita que:

As escolas são desafiadas a repensar essas novas formas de aprendizagem, a rever métodos e práticas, dar novos sentidos aos tempos e espaços, é preciso que a instituição escolar prepare a população para um funcionamento da sociedade cada vez mais digital e também para buscar no ciberespaço um lugar para se encontrar, de maneira crítica, com diferenças e identidades múltiplas.

Como afirma Nóvoa (2011), precisamos de uma escola centrada na aprendizagem, diminuir as práticas excessivamente homogêneas e uniformes e introduzir pouco a pouco um trabalho de diferenciação pedagógica, apostando mais no trabalho coletivo, de cooperação entre os alunos mais e menos avançados. Uma escola focada na aprendizagem é um local onde os alunos aprendem a estudar, a trabalhar e a estar juntos. As Tecnologias Digitais de Informação e Comunicação (TDIC) podem contribuir como ferramentas importantes nesse processo. Por essa razão, a pesquisa junto aos professores a respeito do uso da tecnologia em suas práticas docentes torna-se relevante para compreender o atual cenário da Educação nacional.

\section{A Pesquisa}

A partir das vozes dos professores da educação básica, este artigo busca responder a seguinte pergunta: Que percepções sobre usos de meios digitais em práticas pedagógicas emergem quando os professores refletem sobre suas práticas e experiências vividas com uso de tecnologia? $O$ corpus da pesquisa é constituído pelas narrativas digitais de 11 docentes da educação básica, usuários frequentes de Tecnologias Digitais de Informação e Comunicação - TDIC, em seu cotidiano no trabalho educativo. As narrativas, coletadas a partir de uma pesquisa-formação (JOSSO 2010) ${ }^{2}$ desenvolvida em 2014, foram postadas e comentadas em ambiente virtual de aprendizagem, em espaço próprio denominado Rede de Conversas, em que os docentes discutiam/narravam as próprias experiências com uso de tecnologias. 
O objetivo da Rede de Conversas foi favorecer a leitura e partilha das narrativas digitais de cada docente e, por consequência, a troca de experiências, o conhecimento de novos/diferentes usos dos recursos digitais numa aproximação cada vez maior dos docentes entre si e das tecnologias digitais, potencializando assim uma conectividade entre os participantes. As narrativas dos 11 participantes da pesquisa-formação foram analisadas a partir da abordagem hermenêutica-fenomenológica (FREIRE 2012, RICOUER 1986).

\section{A abordagem hermenêutica-fenomenológica}

Para Freire (2012, p.182), a abordagem hermenêutica-fenomenológica, enquanto um método de pesquisa qualitativa, "contempla um interesse investigativo que é, essencialmente, baseado em experiências vividas”, uma vez que, como assegura McCoy (1993, p.4), "o mundo não é fundamentalmente o que se pensa sobre ele, mas o que nele se vive". Desta forma:

A abordagem hermenêutico-fenomenológica configura-se como uma orientação metodológica de natureza qualitativa, que visa descrever detalhadamente e interpretar fenômenos da experiência humana, objetivando aproximar-se de sua essência, por meio da identificação dos temas hermenêutico-fenomenológicos que os caracterizam e lhes dão identidade. (FREIRE, 2012, p. 194).

A abordagem hermenêutico-fenomenológica utiliza-se das descrições das manifestações de um fenômeno da experiência humana, em formato textual - textualização -, o que permite o desenvolvimento de uma atividade investigativa mais profunda, levando à apresentação de uma interpretação válida que "precisa ser documentada para que se mostre consistente e viável” (FREIRE 2010, p. 25).

"A fenomenologia contempla as experiências vividas de um ponto de vista retrospectivo e descritivo, buscando desvendar a essência e as qualidades de um certo fenômeno, sob a perspectiva de quem o vivencia, percebe, intuitivamente interpreta e a ele se refere" (FREIRE, 2012, p. 185). Nesse sentido, Maximina Freire complementa afirmando que "a fenomenologia, portanto, procura um entendimento mais profundo das experiências cotidianas, preocupando-se com a forma como são imediatamente percebidas, ao invés de defini-las e/ou categorizá-las previamente". (FREIRE, 2012, p. 185).

Complementarmente, para interpretar o mundo, a hermenêutica necessita de textos escritos, pois seu objetivo é decifrar, desvendar, revelar, interpretar, trazer o oculto, buscando os significados nas entrelinhas, no sentido de, a partir da aparência, buscar a essência das experiências humanas (RICOEUR, 1986/2002, FREIRE, 2010, 2012). A linguagem é, portanto, aquilo que ao atravessá-la, somos atravessados por ela, e, nessa dupla travessia, o que dizemos faz sentido, mesmo quando não nos damos conta disso.

A abordagem hermenêutico-fenomenológica (FREIRE, 2012) possibilita, portanto, uma participação ativa e reflexiva do pesquisador como articulador e participante da pesquisa, contribuindo para possíveis interpretações e construções de significado. 
Ao ser interpretado eu estou em transformação. O si mesmo nunca está pronto, si mesmo é tarefa, é tarefa que passa pela interpretação. Interpretando o mundo, nós fazemos a tarefa de melhorar a nós mesmos; e no conflito das interpretações é sempre importante haver diálogo (RICOEUR, 2013). Nesse sentido, para Ricoeur, o si mesmo é uma construção, uma tarefa, nunca é algo pronto, é algo que acontece.

Desta forma, a materialização textual permite que a descrição de experiências humanas alcance um grau de objetivação que auxilie a interpretação e a compreensão do fenômeno investigado. A etapa de interpretação do fenômeno, denominada tematização, procedimento hermenêutico-fenomenológico típico, realizada a partir de diversas leituras e releituras dos textos coletados, se revela por meio da identificação de temas hermenêutico-fenomenológicos (FREIRE, 2012), que expressam e caracterizam a constituição e a essência do fenômeno investigado. Nessa etapa, iniciam-se os procedimentos de refinamento e ressignificação (FREIRE, 2012). O refinamento consiste na identificação das unidades de significado e avaliação da sua relevância, quando são observados os termos que melhor expressam o significado essencial do fenômeno, suas características fundamentais. "Esses procedimentos evidenciam o que metaforicamente associo a um mergulho interpretativo" (FREIRE, 2012, p. 193).

Na visão de Freire (2012, p.187) "os fenômenos da experiência humana são fonte inesgotável de investigação, interpretações e reinterpretações”, assim sendo, dificultam o desvendar dos fenômenos em sua totalidade. Portanto, reconhecendo que não se pode apreender a totalidade de um fenômeno de maneira absoluta, apresento alguns temas hermenêutico-fenomenológicos que emergiram das narrativas.

\section{A análise das narrativas digitais}

Depois de muita leitura, de idas e vindas, de explicações e compreensões, num percurso que certamente ampliou minha experiência com o texto e com o mundo, a partir do embasamento teórico e suporte metodológico apresentados oportunamente, explicito a minha interpretação do fenômeno em foco.

Os temas hermenêutico-fenomenológicos que emergiram através dos procedimentos interpretativos realizados foram: Abertura, Desafio e Compromisso. O tema Abertura possui como subtema a Sintonia, que apresenta um subsubtema a Aproximação. O tema Compromisso se revela nos subtemas Barreiras, Resultado e Cooperação que engloba o subsubtema Diálogo. Desta forma, apresento a seguir a interpretação dos temas que revelam a essência da manifestação do fenômeno estudado.

\section{Abertura}

"Como abertura, o compreender sempre alcança toda a constituição fundamental do ser-no-mundo" (HEIDEGGER, 2009, p.145). Se há abertura, a compreensão já está toda disponível, há um trabalho a ser feito, mas a compreensão é alcançável. Para Heidegger "compreender é o ser existencial do próprio poder-ser da presença de tal maneira que, em si mesma, esse ser abre e mostra a quantas anda seu 
próprio ser". Portanto, é fundamental destacar que a abertura para compreender e atuar neste mundo é uma ação distintiva dos participantes desta pesquisa.

Quando busquei compreender que percepções sobre usos de meios digitais em práticas pedagógicas emergem quando os professores refletem sobre suas práticas e experiências vividas com o uso de tecnologia, analisando as narrativas, a primeira questão que se colocou claramente foi que essas práticas não se originam de experiência de vivências desses enquanto eram alunos, mas origina-se nas vivências pessoais cotidianas, da praticidade que a tecnologia oferece para a sua vida e para a sociedade e até mesmo da curiosidade de conhecê-la ou do prazer que traz ao ser utilizada.

Esse fato demonstra a compreensão dos docentes sobre as possibilidades que tais aparatos tecnológicos poderiam abrir a suas práticas pedagógicas. $\mathrm{O}$ compreender possui a estrutura existencial que chamamos de projeto, dessa forma, "o compreender projeta o ser da presença" e Heidegger (2009, p. 145) afirma que:

Este não apenas se abre para o mundo, no sentido de possível significância, mas a liberação de tudo que é intramundano libera esse ente para suas possibilidades. (...) O caráter projetivo do compreender constitui o ser-no-mundo no tocante à abertura do seu pre, enquanto pre de um poder-ser. O projeto é a constituição ontológico-existencial do espaço de articulação do poder-ser fático. $\mathrm{E}$, na condição de lançada, a presença se lança no modo de ser do projeto. $\mathrm{O}$ projetar-se nada tem a ver com um possível relacionamento frente a um plano previamente concebido, segundo o qual a presença instalaria o seu ser. Ao contrário, como presença, ela já sempre se projetou e só é em se projetando. Na medida em que é, a presença já se compreendeu e sempre se compreenderá a partir de possibilidades.

Essa abertura e a compreensão dela decorrente são traduzidas em expressões como: "Aprender é responsabilidade do aluno, mas eu, como educadora, tenho que ajudá-lo a entender que o que eu faço é para ajudá-lo... E o aluno, em suas críticas, me ajuda a aprender a ajudá-lo e me ajuda a aprender a melhorar" (P. D.). Essa Abertura é uma atitude interior, uma Abertura para si, para o outro e para o meio. Abertura para o novo, para o diferente, para a participação efetiva do aluno, conduz a uma busca constante dos docentes por Sintonia (subtema). Uma possibilidade de interpretação de Sintonia pode ser verificada quando recorremos ao dicionário 3 : Sintonia é definida a partir de algo que envolve acordo, reciprocidade, simpatia ou harmonia. A amplitude desses significados é bem profunda, pois sempre requer a participação ativa das partes envolvidas. Estar em sintonia implica estar em igualdade de frequência numa relação de acordo e correspondência.

Os alunos sabem muito e têm muito a oferecer. Sempre me surpreendo com o que eles trazem (claro, nunca é uma unanimidade...rs, nem toda a sala, normal). Acredito que meu trabalho deve ser de interagir com meus alunos e sempre repensar minhas aulas com o uso de tecnologias (e para isso, buscar, aprender, me informar) para que ela esteja em sintonia com a realidade em que nos encontramos (T. L.). 
Para os participantes da pesquisa, mostrou-se ser fundamental estar em Sintonia com o mundo contemporâneo, com o século XXI. Mas, por que entrar em sintonia com esse mundo? "O que me motiva a adotar tais práticas éo desejo de oferecer ao meu aluno um ensino efetivo, prazeroso, próximo da sua realidade" (L. P.). O que se busca estando em Sintonia com esse "Turbilhão da vida moderna", como definia Berman (1986), é ir além daquilo que está posto, preestabelecido, predeterminado. "A participação dos alunos é fundamental para o sucesso das aulas. Eles produzem vídeos, blogs, jornais digitais, jogos, Prezi, é um festival. Gosto de mediar este processo e de me surpreender com os resultados" (T. L.).

Desta forma, para estar em Sintonia com o mundo contemporâneo e com seus alunos, esses professores buscam uma Aproximação (subsubtema) com o universo dos alunos, com suas linguagens, com os aparatos tecnológicos que os cercam cotidianamente.

Numa atitude de Abertura e compreensão da realidade, em Sintonia com o mundo que o cerca, revelando sua preocupação com a necessidade de Aproximação, o participante questiona: "Nossos alunos respiram isso nê?" (E. C.), "Se pudermos oferecer um algo mais ao nosso aluno, por que não fazê-lo?", e conclui dizendo: "a casa passa a ser uma extensão da escola, sem limites para o conhecimento" (L. P.).

E complementa, falando a respeito do que sente ao utilizar uma tecnologia digital como ferramenta de ensino-aprendizagem:

Sinto satisfação em interagir com os alunos em ambiente online e de perceber que eles interagem entre si, com atenção, respeito e motivação. Estou sempre pensando no aprendizado do meu aluno e, numa visão empática, tento elaborar as aulas me pondo no lugar do aluno, pensando "se eu fosse aluna, como eu gostaria que este assunto fosse abordado?” (L. P.).

A empatia descrita demostra uma Aproximação entre o educador e o educando, que contempla e exige adaptações e flexibilidade, como é possível observar na narrativa a seguir:

Percebi que a dinâmica da tecnologia é muito rápida quando, este ano, perguntei para uma sala se eles já tinham formado um grupo no Facebook. Responderam que eu já estava ultrapassada, porque a moda agora é WhatsApp. Hoje, utilizamos as duas ferramentas. Como diz o ditado, "vivendo e apendendo". (T. L.)

As perspectivas apontadas nas narrativas revelam esse movimento dos docentes, que expressam Sintonia com o seu tempo, com seu aluno, exprimindo um processo de Abertura para a compreensão e expansão das possibilidades de seu trabalho, na busca constante de uma Aproximação com seu aluno. "Podemos fazer isso de tal forma que os alunos nem sequer percebam o que estão aprendendo, e de repente, o conbecimento é compartilhado" (Z.T.). A Tecnologia, nesse sentido, figura como uma ponte para promover essa aproximação entre professor e alunos. Dessa forma, tornam-se autores, descobridores, transformadores e produtores do conhecimento. 
Quando descobri a tecnologia como ferramenta para as minhas aulas, acredito que avancei e dei um passo decisivo na minha vida pessoal e profissional, pois percebi como os alunos, ou seja, os jovens estão aprendendo hoje e preciso me atualizar e aperfeiçoar as minhas estratégias de aulas, além de estar sempre conectada para dar um novo estímulo e motivação para os alunos e para as minhas aulas também (V. S.).

Como parceiros, professores e alunos desencadeiam um processo de aprendizagem cooperativa na busca da produção do conhecimento. Para Moran (2014, p. 50), “a sociedade conectada está ampliando a aprendizagem em grupo; a aprendizagem entre pares, as 'tribos' virtuais”. Para Pretto (2012), o desafio está em se compreenderem as possibilidades trazidas pela liberdade de experimentar os diferentes usos das tecnologias e pela diversidade de oportunidades propiciadas pelas redes, telemáticas ${ }^{4}$ ou não.

\section{Compromisso}

Em obra intitulada: Paulo Freire uma biobibliografia (GADOTTI, 1996, p. 715) define que Compromisso "é a solidariedade com os homens para a busca incessante da humanização" e Compromisso histórico "é o inserir-se, de maneira crítica, na história. O homem assume o dever, como sujeito, de fazer e refazer o mundo". Para Freire (1983), reencontrar-se como sujeito e liberar-se é todo o sentido do Compromisso histórico.

Freire defende uma educação transformadora, que parta das coisas simples do cotidiano, de cada ato humano e possibilite ao sujeito, através de sua capacidade criativa e transformadora, sua libertação da condição de oprimido. $\mathrm{O}$ instrumento de sua libertação será sempre a prática do diálogo. Educar, portanto, envolve a possibilidade de criar e desenvolver a participação política dos oprimidos rumo à construção e realização de um projeto político e social de libertação.

A narrativa da L. P. expressa esse Compromisso quando explicita seus sentimentos:

Sinto que estou cumprindo a minha obrigação de professora, pois o ensino não precisa se ater apenas ao currículo preestabelecido, se pudermos oferecer um algo mais ao nosso aluno, por que não fazê-lo? (...) Estudar não precisa ser sempre monótono, maçante, cansativo... pode ser também prazeroso e motivador.

Sua narrativa segue indicando a atitude reflexiva sobre a importância de sua ação docente, "o que posso fazer além daquilo que já realizo hoje é continuar usando os recursos digitais e ir me atualizando sempre. Não parar de aprender. Para avançar preciso ir a cada dia evoluindo, implantando procedimentos novos... ousando... experimentando..." (L.P.). Retomo aqui o sentido da pesquisa biográfica que possibilita “(...) mostrar como a inscrição forçosamente singular da experiência individual em um tempo biográfico se situa na origem de uma percepção e de uma elaboração peculiar dos espaços da vida social"(DELORY-MOMBERGER, 2012, p. 524).

O Compromisso ético-político do professor pode vir a ser a força motriz capaz de catalisar a construção de um mundo menos discriminatório e mais humano, 
realizado por homens e mulheres comprometidos com a justiça, a democracia, a diversidade e a ética neste século. A fala de Z.T. ilustra esse compromisso docente que ultrapassa os limites estabelecidos pelo Currículo e pelo espaço físico da sala de aula.

\begin{abstract}
Depois de refletir um pouco, chego à conclusão que o que eu faço é exatamente o contrário do que fizeram comigo. Eu quero fazer diferente. Quero fazer a diferença. Não quero que meus alunos se sintam um número. Quero que se sintam pessoas, seres humanos, individuais e especiais (Z. T.).
\end{abstract}

A Cooperação (subtema) está fortemente presente nas narrativas das experiências dos docentes que expressam sua capacidade de partilhar, até mesmo para compensar aquilo que pode lhes faltar. No livro Juntos: os rituais, os prazeres e a politica da cooperação, de Richard Sennett (2012, p. 10), encontramos “(...) a cooperação como uma habilidade. Ela requer a capacidade de entender e mostrar-se receptivo ao outro para agir em conjunto, mas o processo é espinhoso, cheio de dificuldades e ambiguidades, e não raro leva a consequências destrutivas." Ele afirma que a cooperação entre diferentes sempre foi algo complicado, mas a sociedade moderna a debilitou de forma inédita, principalmente com o aumento vertiginoso da desigualdade nos últimos anos em todo o mundo, fazendo crescer cada vez mais a distância entre os poucos que são muito ricos e grande maioria de empobrecidos.

A cooperação azeita a máquina de concretização das coisas, e a partilha é capaz de compensar aquilo que acaso nos falte individualmente. A cooperação está embutida em nossos genes, mas não pode ficar presa a comportamentos rotineiros; precisa desenvolver-se e ser aprofundada. O que se aplica particularmente quando lidamos com pessoas diferentes de nós; com elas, a cooperação torna-se um grande esforço (SENNETT, 2012, p. 9).

Na visão de Sennett (2012, p. 19), "a sociedade moderna está 'desabilitando' as pessoas da prática da cooperação.” E vários fatores contribuem para a destruição das habilidades de cooperação necessárias para vivermos numa sociedade complexa como a atual.

Paulo Freire afirmava que o Diálogo, elemento essencial para que haja cooperação, quando proposto pelas elites, é vertical, e forma, portanto, o educando-massa, impossibilitando-o de se manifestar. A educação que não promove o diálogo, não contribui para autoafirmação do indivíduo. O Diálogo, algo horizontal, é fruto de uma prática democrática, a qual Freire afirma que precisamos ter coragem para experimentar. "Não há nada que mais contradiga e comprometa a emersão popular do que uma educação que não jogue o educando às experiências do debate e da análise dos problemas e que não lhe propicie condições de verdadeira participação" (FREIRE, 1983b, p. 93).

Nessa dimensão, o professor trabalha no coletivo com os alunos, os motiva a colaborarem entre si, o que favorece uma transformação de atitude em relação à participação e ao compromisso do aluno e do professor, uma vez que olhar o professor como parceiro no processo de aprendizagem será mais fácil. Para professor e alunos enxergarem seus colegas como colaboradores para seu crescimento, já significa uma 
mudança importante e fundamental de mentalidade no processo de aprendizagem (MASETTO, 2000).

Sueli, ao refletir sobre suas práticas e os desafios colocados, afirma que "também vejo na maioria das vezes essa aprendizagem colaborativa, principalmente quando o aluno está disposto a aprender e o professor disposto a ultrapassar as barreiras que encontra na caminhada". A.L. complementa afirmando que

o que construímos pode ser relevante para outros, positiva e negativamente. As minhas experiências podem auxiliar ou dar a ideia inicial para projetos semelhantes ou melhores que o original. Tudo se resume a compartilhar ideias! Compartilhando continuamente podemos avançar juntos!

As barreiras (subtema) existentes no processo não podem ser desconsideradas neste texto. Na busca por ultrapassar as Barreiras da prática pautada apenas pelo famoso trio giz, saliva e lousa, as Barreiras se apresentam em diversos âmbitos: desde as financeiras ("Esta é uma tecnologia de alto custo.") até às pedagógicas ("Esta ação não resultará em aprendizagem.”). Barreiras impostas muitas vezes por um sistema educacional que no discurso valoriza o uso das TDIC, mas na prática ainda é uma realidade distante. Como afirma $Z$.T.:

Ao fazermos capacitações recebemos uma linguagem maravilhosa, incentivadora, querendo inovar e acreditar naquilo que estamos aprendendo. Quando chegamos na realidade da sala de aula encontramos um quadro totalmente diferenciado. Por exemplo: a rede Wi-Fi da nossa escola foi bloqueada para os alunos e, consequentemente, para os professores.

Para Asmann (2000, p. 7):

[...] as novas tecnologias não substituirão o/a professor/a, nem diminuirão o esforço disciplinado do estudo. Elas, porém, ajudam a intensificar o pensamento complexo, interativo e transversal, criando novas chances para a sensibilidade solidária no interior das próprias formas do conhecimento.

Por vezes as Barreiras são de ordem técnica: "não temos Wi-Fi para os alunos e nem para os professores, está bloqueado. Ás vezes programamos alguma atividade para o aluno e não conseguimos levá-lo ao laboratório" (Z.T.). Mas, o interesse por fugir do tradicional e buscar motivar os alunos, mesmo com as Barreiras apresentadas, permanece, o entusiasmo é mantido mesmo com as adversidades. " $E u$ gosto muito de trabalhar com jogos porque nossos alunos respiram isso né? Infelizmente quase todos os colégios pelos quais eram conservadores com isso e o trabalho era de formiguinha mesmo, mas vamos que vamos!!!' (E. C.)

Nóvoa (1998/2007) observa que, apesar do aumento das exigências sobre o professor em relação ao cumprimento de novas tarefas, não houve mudanças significativas na formação de professores. Igualmente vivemos relações paradoxais entre o excesso de expectativas da sociedade sobre a escola e desta em relação à ação do professor e, ao mesmo tempo, a progressiva fragilidade do estatuto docente. "Como 
é possível a escola nos pedir tantas coisas, atribuir-nos tantas missões e, ao mesmo tempo, fragilizar nosso estatuto profissional?” (NÓVOA, 2007, p. 12). Essas também são Barreiras encontradas pelos participantes desta pesquisa. "São tantas possibilidades para melhorarmos a nossa prática. É uma pena que a correria do dia a dia muitas vezes nos impossibilita de usar recursos diversificados" (S. M.).

O Resultado (subtema) é o que inspira esses docentes a seguirem em frente, e nesse processo seguem atendendo ao Desafio de fazer uma docência diferenciada em sintonia com o século XXI. "As TICs na escola devem ser usadas para superar o senso comum pedagógico e para efetivar uma pedagogia condizente com as necessidades de um ensino contextualizado num tempo e num espaço de ser, viver, interagir e criar" (PORTO, 2012, P.192).

Lendo as histórias dos nossos colegas percebo que muitos de nós usamos a tecnologia de maneira independente e, de certa forma, inovadora, uma vez que não tivemos uma formação especifica na graduação ou exemplos de professores que usaram no decorrer da nossa vida escolar. Acho que estamos na vanguarda do uso da tecnologia na Educação. Talvez não tenhamos, agora, a dimensão da contribuição que estamos dando para a vida dos nossos alunos, mas certamente estamos marcando a história deles de uma maneira diferenciada (L. P.).

A reflexão de L.P. me faz retomar Bruner quando afirma que através da narrativa construímos e reconstruímos, e de alguma forma reinventamos o ontem e o amanhã (BRUNER, 2014). Nessa direção, Anderson expressa sua expectativa em relação ao Resultado do seu trabalho. "Não vou mudar o mundo todo, mas posso mudar tudo para alguns, e isso me motiva!". E acrescenta S.M. "Hoje sei (...) que mudar o mundo eu não posso, mas se conseguir incutir na cabeça de alguns o desejo de contribuir para um mundo melhor, já estarei feliz".

O Resultado é fruto de um trabalho humano, com seres humanos, como afirma Fabiana: "Acredito e vivencio em minha prática que o 'material humano'é o que faz toda a diferença nos processos e nos resultados de um bom trabalho". E fica para a vida: "Mas recebo até hoje mensagens dos alunos, sou marcado em fotos e é esse carinho gostoso que nos faz acreditar que tudo valeu a pena" (E. C.).

O processo é sempre de aprendizagem, e não apenas para os alunos: " $E$ sempre, sempre quando eles retornavam, eu recolbia o material para editar sempre me surpreendia com o tanto de registros interessantes... Fui aprendendo a confiar neles?" (Marcelo) $\mathrm{O}$ relato de Marcelo traz luz a essa perspectiva de Resultado que se materializa a partir de uma aprendizagem compartilhada, que se constrói na vivência, através das experiências e com confiança. Surpreender-se com a produção de seus alunos só é possível quando se dá Abertura para isso; quando preocupado com a Motivação dos alunos se propõem Desafios, que promovem a sua Autoria; quando se enfrenta as Barreiras e se estabelece uma intensa relação de Cooperação. Como bem afirma M. S., "Escola boa é a quela que quando você sai, tem muita história para contar". 


\section{Considerações finais}

Como afirma Josso (2010), experimentamos durante a vida inúmeras vivências, transações, porém essas vivências só atingem o status de experiência a partir do momento em que fazemos um trabalho reflexivo sobre o que se passou e o que foi observado, percebido, sentido.

Nesse processo contínuo de "caminhar para si" (JOSSO, 2010) os participantes da pesquisa-formação mergulharam numa viagem rumo à compreensão de como se tornaram o que são, através de relatos de um conjunto de experiências vividas com uso de tecnologia em suas práticas, e no decorrer da pesquisa-formação eles tomaram consciência da riqueza das suas experiências, do quanto é importante aquilo que fazem e perceberam que o que fazem pode tocar o outro (professores e alunos) e transformá-lo.

Quando os docentes narram suas experiências com o uso de meios digitais em suas práticas pedagógicas mediadas pelas TDIC, percebo que a abertura dos participantes, tanto para aprimorar sua metodologias como partilhar aquilo que fazem, constituiu-se elemento fundamental que permitiu aos docentes mesclarem os conhecimentos dos conteúdos curriculares com o conhecimento das novas tecnologias, sendo que esse último conhecimento boa parte dos alunos já detém, e aos poucos vem sendo adquirido pelos professores que se apropriam desses novos recursos.

A possibilidade de contar com as novas tecnologias como ferramenta pedagógica dá liberdade criadora e possibilidade de autoria a todos os envolvidos no processo, tanto professores como alunos. As narrativas, ricas em experiências diferenciadas, rompem com o molde da aula tradicional, expressam histórias de vidas dispostas a compartilhar, a trocar, a fazer novas escolhas, a superar as expectativas de seus alunos através do seu trabalho.

Dessa forma, numa perspectiva hermenêutica-fenomenológica, esta análise debruçou o olhar para o uso dos meios digitais nas práticas pedagógicas, com o objetivo de estudar, observar e refletir sobre cenas reais do cotidiano educacional brasileiro, em condições nem sempre favoráveis para o uso de TDIC.

Os participantes da pesquisa, entusiastas e desbravadores, fazem uso diferenciado das TDIC e relataram ter mais alegria, satisfação e proximidade com os alunos, ao passo em que revelaram prazer com o trabalho realizado e com os resultados alcançados. As narrativas destacadas apontam para a mudança do quadro apresentado por Nóvoa (2011, p. 41), quando destaca que: "Hoje, para muitos alunos, a escola não tem qualquer sentido, nem representa um projeto no qual eles próprios ou as suas famílias sintam que vale a pena investir”.

\section{Referências}

ASMANN, H. A metamorfose do aprender na sociedade da informação. Ci. Inf., Brasília, v. 29, n. 2, p. 7-15, maio/ago. 2000. 
BERMAN, M. Tudo que e solido desmancha no ar: a aventura da Modernidade. São Paulo: Companhia das Letras, 1986.

BRUNER, J. Fabricando histórias: direito, literatura, vida. São Paulo: Letra e Voz, 2014.

DELORY-MOMBERGER, C. Abordagens metodológicas da pesquisa biográfica. In: Revista Brasileira de Educação, Rio de Janeiro, v. 17, n. 51, p. 523-536, set/dez. 2012.

FREIRE. M. M. Da aparência à essência: a abordagem hermenêutico-fenomenológica como orientação qualitativa de pesquisa. In: ROJAS, J.; STREINGHETA, L. M. (Orgs.). Educação, pesquisa e prática docente em diferentes contextos. 1. ed. São Paulo: Life Editora, 2012.

. A Abordagem Hermenêutico-fenomenológica como orientação de pesquisa. In: FREIRE, M. M. (Org.). A pesquisa qualitativa sob múltiplos olhares: estabelecendo interlocuções em linguística aplicada. Publicação do GPeAHF, Grupo de Pesquisa sobre a Abordagem Hermenêutico-Fenomenológica. 2010. p. 25.

FREIRE, P. Pedagogia do oprimido. 12. ed. Rio de Janeiro: Paz e Terra, 1983.

Educação como prática da liberdade. 15. ed. Rio de Janeiro: Paz e Terra, 1983b.

GAdOTTI, M. (Org.) Paulo Freire: uma biobibliografia. São Paulo: Cortez, 1996.

HEIDEGGER, M. Ser e tempo. Tradução revisada e apresentação de Marcia Sá Cavalcante Schuback; posfácio de Emmanuel Carneiro LEÃO. 4. ed. Petrópolis: Vozes, 2009.

JOSSO, M. Experiências de vida e formação. 2. ed. rev. e ampl. Natal: EDUFRN; São Paulo: Paulus, 2010.

MASETTO, M. T. Mediação pedagógica e o uso da tecnologia. In: MORAN, J. M.; MASETTO, M. T.; BEHRENS, M. A. Novas tecnologias e mediação pedagógica. 12. ed. Campinas: Papirus, 2000. p. 133 a 173.

McCOY, T. S. Voices of difference: studies in critical philosophy na mass communication. Hampton Press, In: MERLEAU-PONTY, M. (1962) Phenomenology of perception. Routledge e Kegan Paul, 1993

MORAN, J. M. A educação que desejamos: novos desafios e como chegar lá. 5. ed. Campinas: Papirus, 2014.

NÓVOA, A. O regresso dos professores. Pinhais: Melo, 2011.

PORTO, T. M. E. As tecnologias estão na escola. E agora, o que fazer com elas? In: FANTIN, M.; RIVOLTELLA, P. C. Cultura digital e escola: Pesquisa e Formação de professores. Papirus Editora: Campinas, SP., 2012.

PRETTO, N. L.; ROSSINI, C.; SANTANA, B. (Orgs.) Recursos Educacionais Abertos: práticas colaborativas políticas públicas. Salvador: Edufba; São Paulo: Casa da Cultura Digital, 2012.

RICOEUR, P. Tempo e narrativa. Campinas: Papirus, 1994.

. Do texto à acção: ensaios de hermenêutica II. Porto: Rés, 1986.

ROJO, R. (Org.). Escola conectada: os multiletramentos e as TICs. São Paulo: Parábola, 2013.

SENNETT, R. Juntos: os rituais, os prazeres e a política da cooperação. Rio de Janeiro: Record, 2012.

\section{Notas}

${ }^{1}$ http://www.revistaeducacao.com.br/textos/221/jesuitas-do-seculo-21escolas-jesuitas-da-catalunha-apostam-na-renovacao-363869-1.asp 
${ }^{2}$ Qualificamos esse cenário de "pesquisa-formação" porque a atividade de pesquisa contribui para a formação dos participantes no plano das aprendizagens reflexivas e interpretativas e toma lugar, no seu percurso de vida, como um momento de questionamento retroativo e prospectivo sobre seu(s) projeto(s) de vida e sua(s) demanda(s) de formação atual. Todos os grupos biográficos constatam que a apresentação e a escuta dos relatos desencadeiam um processo dialético de identificação (JOSSO, 2010, p. 71).

${ }^{3}$ Dicionário de Português Online. Disponível em: http://michaelis.uol.com.br/moderno/portugues/index. php?lingua=portugues-portugues\&palavra=sintonia

${ }^{4}$ Telemática é o produto compartilhado a partir do desenvolvimento conseguido pelas telecomunicações e pela informática.

* Professora doutora da Universidade Metodista de São Paulo, São Bernardo do Campo, São Paulo, Brasil.

\section{Correspondência}

Adriana Barroso de Azevedo - Rua do Sacramento, 230. Rudge Ramos, CEP: 09641-000, São Bernardo do Campo, São Paulo - Brasil.

E-mail: adriana.azevedo@metodista.br

Recebido em 18 de setembro de 2015

Aprovado em 13 de junho de 2016 